\title{
The Type Species of the Genus Nocardia
}

\author{
BY RUTH E. GORDON AND JOAN M. MIHM \\ Institute of Microbiology, Rutgers, The State University, \\ Nerw Brunswick, N.J., U.S.A.
}

(Received 28 December 1960)

\begin{abstract}
SUMMARY
Expanded descriptions of Nocardia asteroides (Eppinger) Blanchard, based on 142 strains, and of $N$. brasiliensis (Lindenberg) Castellani \& Chalmers, based on 62 strains, are presented and compared. Illustrations are given of the variation in morphology and appearance of the growth among strains of both species. The morphological and physiological similarity of ATCC strain no. 3318, the accepted type strain of $N$. farcinica Trevisan, to strains of $N$. asteroides is shown, and the resulting problem of nomenclature is discussed.
\end{abstract}

\section{INTRODUCTION}

During the assembly of a collection of strains of mycobacteria, nocardias and streptomycetes, many of the specifically named strains of nocardias received from culture collections and individual investigators were labelled Nocardia asteroides (Eppinger) Blanchard. Among these were freshly isolated strains and strains which had been maintained in vitro for different periods of time, some for more than 30 years (Gordon \& Mihm, 1957). They differed greatly in their macroscopic appearance, formation of pigments, acid-fastness and fragmentation of their vegetative hyphae. Some exhibited rudimentary and very short aerial hyphae; some, abundant aerial hyphae of various lengths; and the aerial hyphae of others segmented into chains of bead-like spores (Gordon \& Mihm, 1958). Despite these differences, the strains of $N$. asteroides, new and old, possessed a distinctive group of correlating characteristics. Variants of several strains selected in our laboratory and strains, originally the same, from different donors also had the same distinguishing characters.

Among the other strains in our collection, 26 specifically unidentified isolates from soil or from infections in man or animals, and 23 isolates representing 17 other species, possessed the same group of characteristics identifying Nocardia asteroides. The 49 strains were accepted, therefore, as strains of $N$. asteroides. Three of these, two of which were American Type Culture Collection (ATCC) strain no. 3318 obtained from different donors, bore the name $N$. farcinica Trevisan (1889), the name of the type-species of the genus Nocardia and a name having priority over $N$. asteroides. In addition, ATCC strain no. 3318 had been accepted as the type strain of the species $N$. farcinica (Waksman, 1957). Although the original description of $N$. farcinica (Nocard, 1888) is meagre, it seemed in our opinion to apply to ATCC strain no. 3318 and to strains of $N$. asteroides. A proposed solution of this problem of nomenclature was postponed, however, until further examination could confirm the similarities or reveal differences between ATCC strain no. 3318 and

Vol. 26, No. 3 was issued 27 November 1961 
Table 1. Additional strains identified as Nocardia asteroides (Eppinger) Blanchard

Laboratory no. 897; 404

784

856, 857

858-861

862

874

886

928

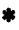

$+$

1011

8410

8423

615

^

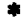

$*$

*

1018

3805

983-985, 1023

947

1001

1024

1826

8573

$*$

$*$
Name when received, source, and strain name or number

Nocardia asteroides (Eppinger) Blanchard; C. W. Emmons, Nat. Inst. of Health, Bethesda, Md. (9907, McCallum; 9835, chicken)

N. asteroides; B. W. Lacey, Westminster School of Medicine ( $\left.\mathbf{A}_{6}\right)$; NCTC $=($ British) National Collection of Type Cultures

N. asteroides ; E. Meyer, Univ. of Illinois (Lerner, brain abscess ; Suddeth, pulmonary infection)

N. asteroides; W. D. Jones, Jun., Dept. of Public Health, Atlanta, Ga. (1, 2, 3, 4; sputum)

N. asteroides; W. H. Trejo, E. R. Squibb \& Sons, New Brunswick, N.J. (Meade, lesion on knee)

N. asteroides; I. Uesaka, Kyoto Univ., Kyoto, Japan (Hiroshima, skin ulcer)

N. asteroides; B. Gueft, Veterans Administration Hospital, Cincinnati, Ohio (sputum)

N. asteroides; F. B. Seibert, Univ. of Pennsylvania (P.H.S. 2412); N. F. Conant (2412, abscess)

N. asteroides; E. Wolinsky, Cuyahoga County Hospital, Cleveland, Ohio (Stevens, sputum)

N. asteroides; S. M. Finegold, Veterans Administration Center, Los Angeles, Calif. (Wherry, empyema)

N. bostroemi; N. M. McClung, Univ. of Georgia (159); J. D. Schneidau, Jun. (303); A. Batista (630); Inst. Pasteur (321)

N. paraffinae (Jensen) Waksman \& Henrici; NCTC (3488)

N. rangoonensis (Erikson) Waksman \& Henrici; American Type Culture Collection (ATCC); NCTC (1678)

Nocardia sp.; E. N. Azarowicz, Univ. of Calif. (27)

Nocardia spp.; M. P. Lechevalier, Rutgers Univ. (1, 10 (7); soil)

Nocardia spp.; C. I. McDurmont, Dept. of Public Health, Montgomery, Ala. (58-19 467, 58-19 758)

Nocardia sp.; J. B. Fischer, Dept. of Health, Toronto, Canada (1211)

Nocardia sp.; E. Wolinsky (Gallagher, sputum)

Streptomyces fradiae (Waksman \& Curtis) Waksman \& Henrici; J. K. Johannesson, Wellington City Council, Wellington, New Zealand (A5, A22, A23, A47; water)

Streptomyces sp.; A. Grein, Rutgers Univ. (278, water)

Streptomyces sp.; J. B. Routien, Chas. Pfizer \& Co., Brooklyn, N.Y. (AP 9831, 88540-16; soil)

Unidentified strain ; E. Baldacci, Univ. of Milan (22 of series of 25 strains of actinomycetes distributed for study)

Unidentified isolations; C. C. Campbell, Walter Reed Army Medical Center (87, 50, 49, pulmonary lesions; 182, ulcerating abscess)

Unidentified isolation; H. Keltz, Dept. of Public Health, Columbus, Ga. (P.H.S. 6, sputum of healthy person)

Unidentified isolation; M. L. Littman, Mount Sinai Hospital, New York, N.Y. (MS. 1072)

Unidentified isolation; C. W. Emmons (CM B-404); L. K. Joe

(mycetoma)

Unidentified isolation; J. H. Hanks, Leonard Wood Memorial, Culion Palawan, Philippines (blood of patient with Hansen's disease)

Unidentified isolation; R. Holt, Touro Infirmary, New Orleans, La. (breast abscess)

Unidentified isolation; J. F. Welsh, Lankenau Hospital, Philadelphia, Pa. (A-59-38, adrenal gland)

Unidentified isolation; J. B. Fischer (7-882, thoracic sinus)

Unidentified isolation; J. Walker, London School of Hygiene and Tropical Medicine (5859); E. Agius (pulmonary lesion)

* Examined, but not added to this collection. 
strains of $N$. asteroides, and until opinions could be obtained from other investigators who had made similar studies.

Strains of Nocardia asteroides and $N$. brasiliensis identified since our last report (Gordon \& Mihm, 1959) are listed here; the results of further comparative study of the two species are presented; a presumptive test for the recognition of strains of $N$. asteroides is described; and the nomenclature and importance of the type species of the genus Nocardia are discussed.

Table 2. Additional strains identified as Nocardia brasiliensis (Lindenberg) Castellani \& Chalmers

$\begin{array}{ll}\text { Laboratory no. } & \text { Name when received, source, and strain name or number } \\ 887 & \text { Nocardia brasiliensis (Lindenberg) Castellani \& Chalmers; J. L. Mir- } \\ \text { anda, Inst. Oswaldo Cruz (229) } \\ \text { N. brasiliensis; N. F. Conant, Duke Univ. (0 S180); C. M. Whorton } \\ \text { (tumour on heel of patient) } \\ \text { N. brasiliensis; L. F. Bojalil, Univ. Nacional Autónoma de Mexico } \\ \text { (N-37, N-29, N-30, and N-38; mycetomas) } \\ 1113-1116 & \text { N. brasiliensis; L. F. Bojalil (variants of N-114; mycetoma) } \\ 1118 \text { A, 1117B } & \text { N. brasiliensis; L. F. Bojalil (N-112, N-118, fistulas; N-115, mycetoma) } \\ 1108 & \text { Nocardia sp.; J. P. Truant, Henry Ford Hospital, Detroit, Mich. } \\ & \text { (Philip Harris, pustule on forearm) }\end{array}$

\section{METHODS}

The strains of Nocardia asteroides and of $N$. brasiliensis used included those given in Tables 1 and 2 and those listed previously (Gordon \& Mihm, 1957, 1959). The observations and tests described by Gordon \& Mihm (1957) were used in this study with the following additions.

Survival at $50^{\circ}$. Two slopes of yeast glucose agar were inoculated from a 14- to 30-day culture in glucose broth. One of the two slopes was quickly heated to $50^{\circ}$ in a water bath, then held in another water bath at $50^{\circ}$ inside a constant temperature incubator for $8 \mathrm{hr}$. After heating, the slope was quickly cooled, incubated at $28^{\circ}$ for 21 days and observed for growth. The unheated culture was also incubated at $28^{\circ}$ for 21 days and inspected for growth.

Decomposition of hypoxanthine. Each culture was streaked once across a plate containing c. $20 \mathrm{ml}$. of the following medium: peptone, $5 \mathrm{~g}$; ; beef extract, $3 \mathrm{~g}$.; agar, 15 g.; hypoxanthine (Nutritional Biochemicals Corp., Cleveland, Ohio), 5 g.; distilled water, $1000 \mathrm{ml}$; $\mathrm{pH} 7 \cdot 0$. Care in preparation was required to insure an even distribution of the crystals of hypoxanthine throughout the medium. After 14 and 21 days of incubation at $28^{\circ}$, each plate was observed for the disappearance of the crystals of hypoxanthine underneath and around the growth. The importance of a heavy inoculum when testing for the decomposition of casein and of crystals of hypoxanthine, tyrosine or xanthine needs to be stressed. Although some cultures grew well on these media, they did not dissolve the casein or the crystals except around the larger clumps of inoculum.

Sensitivity to lysozyme. Glycerol broth containing $0.005 \%(w / v)$ lysozyme was prepared by dissolving 0.1 g. lysozyme (Nutritional Biochemicals Corp., Cleveland, Ohio) in about $66 \mathrm{ml}$. sterile $0.01 \mathrm{~N}-\mathrm{HCl}$ in a $100 \mathrm{ml}$. volumetric flask plugged with cotton. The solution was boiled over an open flame for 20 min., cooled to room 
temperature and brought to $100 \mathrm{ml}$. by addition of sterile $0.01 \mathrm{~N}-\mathrm{HCl}$. Five $\mathrm{ml}$. of the lysozyme solution was mixed with $95 \mathrm{ml}$. sterile glycerol broth (peptone, $5 \mathrm{~g}$.; beef extract, $3 \mathrm{~g}$.; glycerol, $70 \mathrm{ml}$; distilled water, $1000 \mathrm{ml}$; $\mathrm{pH} 7 \cdot 0$ ) and dispensed in $2.5 \mathrm{ml}$. amounts in sterile plugged tubes. A loopful of a 14- to 30-day culture in glucose or glycerol broth was inoculated into a tube of lysozyme broth and into a tube of glycerol broth. After 14 and 28 days of incubation at $28^{\circ}$, the tubes were observed and compared for growth.

\section{RESULTS}

\section{Nocardia asteroides (Eppinger) Blanchard}

Among the 44 strains of Nocardia asteroides listed in Table 1, the specific names $N$. bostroemi, $N$. paraffinae, $N$. rangoonensis and $S$ treptomyces fradiae had not been encountered previously among the strains assigned to $N$. asteroides. Although an authority for the transfer of Actinomyces bostroemi Baldacci (1937) to the genus Nocardia was not found, strain no. 1011 appeared to be in agreement with Puntoni's (1931) description, the description to which Baldacci referred when he proposed the name $A$. bostroemi. Strain no. 3410, received as $N$. paraffinae (Jensen, 1931) Waksman \& Henrici (1948), seemed to conform to Jensen's original account. Strain no. 3423 was obtained as $N$. rangoonensis (Erikson, 1935) Waksman \& Henrici (1948) from the ATCC more than 20 years ago and corresponded to the first description of the species. Strain no. 6860 received in 1951 from the ATCC as $N$. rangoonensis, however, proved to be unlike strain no. $\mathbf{3 4 2 3}$ and to disagree with Erikson's delineation. Strains nos. 1011, 3410 and 3423 were accepted, therefore, as authentic. The four strains of $N$. asteroides received as $S$. fradiae (Waksman \& Curtis, 1916) Waksman \& Henrici (1948) were very different from authentic strains of $S$. fradiae and were regarded as misnamed.

In 1957 Gordon \& Mihm reported the (British) National Collection of Type Cultures (NCTC) strain no. 6531, received as Nocardia gardneri, to be one of $N$. asteroides and at variance with its original description (Waksman et al. 1942). Later, a subculture of the strain maintained at Oxford University and one from the ATCC were examined and found to agree with the original delineation of $N$. gardneri and to be unlike strains of $N$. asteroides. The first strain labelled $N$.gardneri is regarded, therefore, as a victim of human fallibility.

Microscopic appearance. When stained by the Ziehl-Neelsen method, 27 of the 44 strains listed in Table 1 showed slender branching filaments; 13, rods of various lengths and short filaments; 3, coccoid forms, rods and short filaments; and 1, only short rods. The filaments of about $60 \%$ of the cultures did not fragment during the relatively severe treatment of the Ziehl-Neelsen technique. Eleven of the $\mathbf{4 4}$ cultures were not acid-fast; a few rods or portions of a few filaments of 19 cultures retained the carbol fuchsin; and $10-80 \%$ of the rods and filaments of the remaining 14 cultures were acid-fast.

The colonies of about $75 \%$ of the 44 cultures were loosely filamentous with long, branching, intertwining, vegetative (substrate) hyphae (Pl. 1, fig. 1). The remaining cultures formed densely filamentous colonies or both densely and loosely filamentous ones. Fragmentation of the undisturbed vegetative hyphae was observed in only five cultures. All of the 44 cultures formed aerial hyphae which were: in 3 cultures sparse and short; in 4 more abundant, long and straight; in 14 sparse or 
abundant, branching, twisted and irregular in length; in 7 short or long and coalesced in tufts; in 15 short or long with many side branches, some of which branched in whorls or clusters. The aerial hyphae of $30 \%$ of the cultures segmented into chains of bead-like spores. Aerial hyphae arising from the substrate hyphae pictured in Pl. 1, fig. 1, are illustrated in Pl. 1, fig. 2. Immediately after the vegetative hyphae in fig. 1 were photographed, only the focus of the microscope was changed (lifted), and the aerial hyphae were photographed for fig. 2.

Macroscopic appearance. The growth of the 44 cultures on yeast glucose agar, after 14 days of incubation at $28^{\circ}$, varied from thin and restricted to abundant and spreading. It was flat, finely or coarsely wrinkled, or warty; in colour beige, yellow, pale orange or pink. A whitish coating of aerial hyphae over the growth of all but four of the cultures was easily seen by the unaided eye. Some of the variations in appearance of the growth occurring among strains of Norcardia asteroides in this collection are illustrated in Pl. 3, figs. 5-10 and PI. 4, figs. 11-16. The diversity among variants of the same strain (Pl. 3, figs. 8-10; Pl. 4, figs. 11-14) is as striking as that among different strains.

Physiological characteristics. The properties of the 44 strains listed in Table 1 were like those of the 98 previously examined strains of Nocardia asteroides. Results of the observations of the 142 strains are given in Table 3 and compared with those of $\boldsymbol{N}$. brasiliensis. The following group of reactions was distinctive for strains of $N$. asteroides and separated them from strains of other species of Nocardia and those received as streptomycetes, namely: inability to attack casein, hypoxanthine, tyrosine, or xanthine; failure to form acid from adonitol, arabinose, erythritol, inositol, lactose, maltose, mannitol, a-methyl-D-glucoside, raffinose, sorbitol, or xylose; resistance to lysozyme and to $50^{\circ}$ for $8 \mathrm{hr}$.; non-utilization of benzoate. Because of the predominance of negative criteria in this identifying group of reactions, the following characteristics were included: acid production from glucose and glycerol, and utilization of acetate, malate, propionate, pyruvate and succinate as carbon sources. Variation by a strain in any one or two of these 24 reactions was allowed and did not prevent its identification as $N$. asteroides.

Strains nos. 3318 and 3399 . The two strains received as Nocardia farcinica could not be distinguished from those of $N$. asteroides by any of the observations or tests used in this study. Cultures of both strains formed long branching filaments that did not retain the carbol fuchsin. In their lack of acid-fastness, they resembled $\mathbf{3 7} \%$ of the other strains assigned to $N$. asteroides. Their colonies were filamentous; fragmentation of the substrate hyphae was not seen. Culture no. 3318 produced sparse, straight, branching aerial hyphae, while those of culture no. 3399 were rudimentary or very short. The aerial hyphae of both cultures could not be observed without the aid of a microscope. After 14 days of incubation at $28^{\circ}$, the growth of both cultures on yeast glucose agar was abundant, spreading, coarsely wrinkled, and pale orange in colour (Pl. 4, fig. 16). Strains nos. 3318 and 3399 possessed all 24 physiological characteristics of the group distinguishing strains of $N$. asteroides (Table 3).

Suggested presumptive test. As the use of so many observations and tests for the identification of a strain is not feasible in a diagnostic laboratory, a presumptive test for strains of Nocardia asteroides is offered. In our collection of about 1500 strains of mycobacteria and actinomycetes, $99 \%$ of those which form aerial hyphae 
Table 3. Comparison of physiological characteristics

\begin{tabular}{|c|c|c|c|c|}
\hline Property & $\begin{array}{c}\text { Nocardia } \\
\text { asteroides } \\
\text { (\% positive } \\
\text { strains) }\end{array}$ & $\begin{array}{c}\text { Strain } \\
\text { no. } 8818\end{array}$ & $\begin{array}{c}\text { Strain } \\
\text { no. } \mathbf{3 3 9 9}\end{array}$ & $\begin{array}{c}\text { Nocardia } \\
\text { brasiliensis } \\
\text { (\% positive } \\
\text { strains) }\end{array}$ \\
\hline $\begin{array}{l}\text { Decomposition of } \\
\text { Casein } \\
\text { Hypoxanthine } \\
\text { Tyrosine } \\
\text { Xanthine }\end{array}$ & $\begin{array}{l}0 \\
4 \\
2 \\
0\end{array}$ & $\begin{array}{l}- \\
- \\
-\end{array}$ & $\begin{array}{l}- \\
- \\
-\end{array}$ & $\begin{array}{r}98 \\
94 \\
100 \\
0\end{array}$ \\
\hline Hydrolysis of starch & 56 & + & - & $\mathbf{5 5}$ \\
\hline $\begin{array}{l}\text { Acid from } \\
\text { Adonitol } \\
\text { Arabinose } \\
\text { Erythritol } \\
\text { Galactose } \\
\text { Glucose } \\
\text { Glycerol } \\
\text { Inositol } \\
\text { Lactose } \\
\text { Maltose } \\
\text { Mannitol } \\
\text { Mannose } \\
\text { a-Methyl-D-glucoside } \\
\text { Raffinose } \\
\text { Rhamnose } \\
\text { Sorbitol } \\
\text { Xylose }\end{array}$ & $\begin{array}{r}0 \\
0 \\
8 \\
24 \\
97 \\
99 \\
3 \\
0 \\
7 \\
1 \\
16 \\
0 \\
0 \\
32 \\
0 \\
0\end{array}$ & $\begin{array}{l}- \\
- \\
- \\
+ \\
+ \\
- \\
- \\
- \\
- \\
- \\
- \\
-\end{array}$ & $\begin{array}{l}- \\
- \\
- \\
- \\
+ \\
+ \\
- \\
- \\
- \\
- \\
- \\
- \\
- \\
- \\
-\end{array}$ & $\begin{array}{r}0 \\
0 \\
0 \\
92 \\
97 \\
98 \\
100 \\
0 \\
4 \\
94 \\
68 \\
0 \\
0 \\
0 \\
0 \\
0\end{array}$ \\
\hline Nitrite from nitrate & 88 & + & - & 90 \\
\hline $\begin{array}{c}\text { Growth at } \\
\mathbf{5 0}^{\circ} \\
45^{\circ} \\
40^{\circ} \\
\mathbf{8 5}^{\circ} \\
28^{\circ} \\
10^{\circ}\end{array}$ & $\begin{array}{r}21 \\
42 \\
88 \\
100 \\
100 \\
17\end{array}$ & $\begin{array}{l}+ \\
+ \\
+ \\
+ \\
+ \\
-\end{array}$ & $\begin{array}{l}+ \\
+ \\
+ \\
+ \\
+ \\
-\end{array}$ & $\begin{array}{r}0 \\
2 \\
60 \\
100 \\
100 \\
41\end{array}$ \\
\hline Survival of $50^{\circ}$ for $8 \mathrm{hr}$. & 98 & + & + & $\mathbf{0}$ \\
\hline Resistance to lysozyme & 99 & + & + & 100 \\
\hline $\begin{array}{l}\text { Utilization of } \\
\text { Acetate } \\
\text { Benzoate } \\
\text { Citrate } \\
\text { Malate } \\
\text { Propionate } \\
\text { Pyruvate } \\
\text { Succinate }\end{array}$ & $\begin{array}{r}100 \\
0 \\
84 \\
95 \\
100 \\
99 \\
94\end{array}$ & $\begin{array}{l}+ \\
- \\
- \\
+ \\
+ \\
+ \\
+\end{array}$ & $\begin{array}{l}+ \\
- \\
- \\
+ \\
+ \\
+ \\
+\end{array}$ & $\begin{array}{r}100 \\
2 \\
98 \\
100 \\
100 \\
100 \\
100\end{array}$ \\
\hline
\end{tabular}

and do not decompose casein or crystals of tyrosine or xanthine are strains of $N$. asteroides. The reactions of strains of $N$. asteroides to these three tests are compared in Table 4 with those of the other closely related taxa best represented in our collection. If this collection typifies the strains of aerobic actinomycetes encountered in the diagnostic laboratory, a strain which forms aerial hyphae but does not attack casein or crystals of tyrosine or xanthine can be presumed, with reasonable safety, to be a strain of $N$. asteroides. 
Table 4. Reactions to suggested presumptive test for

Nocardia asteroides

\begin{tabular}{lccc}
\multicolumn{1}{c}{ Taxon } & \multicolumn{3}{c}{ Decomposition of } \\
\cline { 2 - 4 } Nocardia asteroides & - & - & - \\
N. brasiliensis & + & + & - \\
N. madurae & + & + & - \\
*Nocardia sp. & + & - & + \\
Streptonycetes & + & + & - \\
& + & + & +
\end{tabular}

* As these strains, believed to typify a definite taxon, are rarely encountered, more are sought for study.

\section{Nocardia brasiliensis (Lindenberg) Castellani \& Chalmers}

As the 12 strains listed in Table 2 were labelled Nocardia brasiliensis or Nocardia sp. when received, new names and new problems in nomenclature were not encountered.

Microscopic appearance. Cultures of 11 of the 12 strains grown on glycerol agar for 5 days at $28^{\circ}$ exhibited thin, long or short filaments. The remaining culture was composed of rods and short thin filaments. Two of the 12 cultures did not retain the carbol fuchsin; one showed a few partially acid-fast filaments; and 10-75\% of the filaments of the remaining cultures were acid-fast.

The colonies of the 12 cultures were loosely or densely filamentous or both. Fragmentation of the vegetative hyphae was not observed. All cultures formed aerial hyphae which varied from sparse to abundant, short to long, and straight to gnarled. The aerial hyphae of one culture were long and coalescing; those of three others coiled at the tips in circles or balls. Segmentation of the aerial hyphae into bead-like spores was not found.

Macroscopic appearance. The growth of the 12 cultures on yeast glucose agar after 2 weeks of incubation at $28^{\circ}$ was beige or pale yellow, flat and spreading or wrinkled and heaped-up. Seven of the cultures were thickly coated with whitish aerial hyphae; two were sparsely coated; and three did not have aerial hyphae visible to the unaided eye. These differences in appearance among strains were also demonstrable among variants of the same strain (Pl. 5, figs. 17-20).

Physiological characteristics. The reactions of the 12 strains presented in Table 2 resembled those of the $\mathbf{5 0}$ strains of Nocardia brasiliensis previously described. Characteristics of the 62 strains are listed in Table 3 and compared with those of $N$. asteroides. The following properties were the most reliable for distinguishing strains of $N$. brasiliensis from those of $N$. asteroides : decomposition of casein, hypoxanthine and tyrosine; acid formation from inositol and mannitol; inability to survive $50^{\circ}$ for $8 \mathrm{hr}$. In addition, the following criteria were useful for the separation of strains of $N$. brasiliensis from other species of Nocardia and those received as streptomycetes: inability to decompose xanthine: no acid formation from adonitol, arabinose, erythritol, lactose, maltose, a-methyl-D-glucoside, raffinose, rhamnose, sorbitol or xylose; resistance to lysozyme; failure to utilize benzoate. Production of acid from glucose and glycerol and the use of acetate, citrate, malate, propionate, 
pyruvate and succinate as sources of carbon were positive characteristics of strains of this species. Variation in any one or two of these 27 characteristics did not hinder the identification of a strain as one of $N$. brasiliensis. We regret that we cannot offer at this time a small group of criteria as a presumptive test for the recognition of strains of this species.

\section{Morphological variation among streptomycetes}

The variation in morphology and appearance of the growth exhibited by strains of Nocardia asteroides (Pl. 3, figs. 5-10; Pl. 4, figs. 11-16) and N. brasiliensis (Pl. 5, figs. 17-20) was also observed among strains deposited in our collection as streptomycetes. Variants resembling those pictured in Pl. 6, figs. 21-24 and belonging to each well represented species of streptomycetes in our collection were received or developed spontaneously or artificially in our laboratory. These strains were soft in texture and did not form aerial hyphae which were visible to the unaided eye. The undisturbed substrate hyphae of their colonies fragmented into rods and short filaments (Pl. 2, figs. 3, 4).

\section{DISCUSSION}

One of the guiding principles of this taxonomic study is the firm belief that a strain's specific identity should always be inherent in the strain itself. The identification of a strain should not depend on its source or on characteristics easily lost during cultivation in vitro. The delineation of a species necessitates, therefore: (1) a study of newly isolated strains, strains maintained in the test tube for many years and their variants; (2) the selection of a distinctive group of correlating criteria common to all these strains. Only the more stable characteristics which persist after years of cultivation or after exposure to different methods of inducing variation can be used for the recognition of a species. Such a distinguishing group of characteristics was found for Nocardia asteroides. Strains nos. 3318 and 3399, which were received as $N$. farcinica, possessed the same characters. Further investigation, which has confirmed the similarity of strains nos. 3318 and 3399 to the older strains of $N$. asteroides in our collection, and discussions with other investigators who have made corresponding studies, have strengthened our belief that $N$. farcinica and $N$. asteroides are two different names for the same species.

The first principle of the International Code of Nomenclature of Bacteria and Viruses (1958) is the fixity of names. Although the name Nocardia farcinica has priority, replacement of the well-established and widely accepted name $N$. asteroides by one which has nearly disappeared from culture collections and current literature does not, to our minds, serve the principle of the fixity of names. We prefer to leave the onus of such a change to others and to use $N$. asteroides as nomen conservandum. Regardless of its nomenclature, the species itself is regarded as the type species of the genus Nocardia.

Early in this investigation (Gordon \& Smith, 1955) it was believed that the genus Nocardia could be separated from the genus Streptomyces by a group of physiological reactions. As pointed out, however, the genus Nocardia was then represented in our collection by a preponderance of strains of Nocardia asteroides. After the examination of more strains of other species of Nocardia ( $N$. brasiliensis, $N$. vaccinii, $N$. coeliaca and $N$. madurae) it was concluded that the two genera could not be 
divided by any of the physiological criteria used in this study. The characteristics of acid-fastness, fragmentation of the vegetative hyphae, abundance of aerial hyphae, and segmentation of the aerial hyphae into chains of spores, currently used for the demarcation of Nocardia and Streptomyces, are variable for $N$. asteroides and for strains of streptomycetes. We do not understand the current practice in taxonomy of ignoring the strains represented in Pl. 5, fig. 20 and Pl. 6, fig. 22. Such strains are legitimate members of a species, occasionally type strains, and a classifcation which excludes them is incomplete.

Of the characteristics proposed by others for the division of Nocardia and Streptomyces, the only one which to our knowledge offers a possible means of separating the two genera is the composition of the cell wall, as reported by Cummins \& Harris (1958) and others. Many more strains of all the species concerned need to be examined, of course, before this criterion should be accepted for generic delineation. From our own studies thus far, we are inclined to support the opinions of Bradley \& Anderson (1958) and others who have combined the two genera. A firm stand on this question cannot be taken, however, until each species of Nocardia and those received as belonging to the Streptomyces can be thoroughly studied and their more stable, distinctive characteristics found.

The definition of a species of micro-organisms as a group of freshly isolated strains, strains maintained in vitro for different periods of time, and their variants, which have in common a set of correlating characteristics separating them from other groups of strains, emphasizes the inadequacy of the representation of a species by a single strain. The few photographs presented here of variants of the same strain and of different strains of Nocardia asteroides illustrate that one strain cannot typify the morphology and macroscopic appearance of the species. In a comparative taxonomic study which includes type species of Nocardia, representation of $N$. asteroides by strains which exhibit as many as possible of the known variations in morphology and physiology is strongly recommended.

This research was supported in part by the National Science Foundation. We gratefully acknowledge this assistance, the contribution of $\mathrm{Dr}$ and $\mathrm{Mrs} \mathbf{H}$. A. Lechevalier in making the photographs, and the kindness of the investigators who sent us their strains. We also thank The Foundation for Microbiology for its aid in publishing the coloured plates.

\section{REFERENCES}

BaLdacci, E. (1937). La conception d'espèce chez les actinomycètes par rapport à leur classification et à leur détermination. Boll. Sez. ital. Soc. int. Microbiol. 9, 138.

Bradley, S. G. \& ANDerson, D. L. (1958). Taxonomic implication of actinophage hostrange. Science, $128,413$.

Cummins, C. S. \& Harris, H. (1958). Studies on the cell-wall composition and taxonomy of Actinomycetales and related groups. J. gen. Microbiol. 18, 173.

Erikson, D. (1935). The pathogenic aerobic organisms of the Actinomyces group. Spec. Rep. Ser. med. Res. Coun., Lond. no. 203, 5.

GorDon, R. E. \& MrHM, J. M. (1957). A comparative study of some strains received as nocardiae. J. Bact. 73, 15.

Gordon, R. E. \& MrHM, J. M. (1958). Sporulation by two strains of Nocardia asteroides. J. Bact. 75, 239.

Gondon, R. E. \& Mrem, J. M. (1959). A comparison of Nocardia asteroides and Nocardia brasiliensis. J. gen. Microbiol. 20, 129. 
Gordon, R. E. \& Smrt, M. M. (1955). Proposed group of characters for the separation of Streptomyces and Nocardia. J. Bact. 69, 147.

International Code of Nomenclature of Bacteria and Viruses (1958), p. 9. Ed. The Editorial Board of the International Committee on Bacteriological Nomenclature. Ames: Iowa State College Press.

Jensen, H. L. (1931). Contributions to our knowledge of the Actinomycetales. II. The definition and subdivision of the genus Actinomyces, with a preliminary account of Australian soil actinomycetes. Proc. Linn. Soc. N.S.W. 56, 345.

Nocard, M. E. (1888). Note sur la maladie des boufs de la Guadeloupe connue sous le nom de farcin. Ann. Inst. Pasteur, 2, 293.

Puntonı, V. (1931). Pluralità specifica dell' Actinomyces bovis. Ann. Igiene, 41, 1.

Trevisan, V. (1889). I Generi e le Specie delle Batteriacee, p. 9. Milano: Zanaboni e Gabuzzi.

Waksman, S. A. (1957). Actinomycetaceae Buchanan. In Bergey's Manual of Determinative Bacteriology, 7th ed. p. 718. Baltimore: The Williams and Wilkins Company.

Waksman, S. A. \& Curtrs, R. E. (1916). The Actinomyces of the soil. Soil Sci. 1, 99.

Waksman, S. A. \& Henrici, A. T. (1948). Actinomycetaceae Buchanan. In Bergey's Manual of Determinative Bacteriology, 6th ed., p. 901. Baltimore: The Williams and Wilkins Company.

Waksman, S. A., Horning, E., Welsch, M. \& Woodruff, H. B. (1942). Distribution of antagonistic actinomycetes in nature. Soil Sci. 54, 281.

\section{EXPLANATION OF PLATES}

Plate 1

Fig. 1. Substrate hyphae of Walker strain of Nocardia asteroides on Bennett's agar at 3 days. $\times 550$.

Fig. 2. Aerial hyphae directly above and formed by substrate hyphae of Fig. 1 on Bennett's agar at 3 days. $\times 550$.

\section{Plate 2}

Fig. 3. Fragmentation of substrate hyphae of strain no. 8609 received as Streptomyces rimosus on Bennett's agar at 10 days. $\times 250$.

Fig. 4. Early fragmentation of substrate hypha of strain no. 3699 on Bennett's agar at 10 days. $\times 1000$.

Plate 8

Figs. 5-7. Colonies of three strains of Nocardia asteroides on yeast glucose agar at 10 days. $\times 1.5$. Figs. 8-10. Colonies of three variants of strain no. 8409 of $N$. asteroides on yeast glucose agar at 10 days. $\times 1 \cdot 5$.

Plate 4

Figs. 11, 12. Colonies of two variants of strain no. 443 of Nocardia asteroides on yeast glucose agar at 10 days. $\times 1.5$.

Figs. 18, 14. Colonies of two variants of strain no. 3045 of $N$. asteroides on yeast glucose agar at 10 days. $\times 1.5$.

Figs. 15, 16. Colonies of two strains of $N$. asteroides on yeast glucose agar at 10 days. $\times 1.5$.

\section{Prate 5}

Figs. 17, 18. Colonies of two variants of strain no. 1117 of Nocardia brasiliensis on yeast glucose agar at 10 days. $\times 1.5$.

Figs. 19, 20. Colonies of two variants of strain no. 774 of $N$. brasiliensis on yeast glucose agar at 10 days. $\times 1.5$.

\section{Plate 6}

Figs. 21, 22. Colonies of two variants of strain no. 3535 received as Streptomyces fradiae on yeast glucose agar at 10 days. $\times 1.5$.

Figs. 23, 24. Colonies of two variants of NRRL strain no. 2234 received as S. rimosus on yeast glucose agar at 10 days. $\times 1.5$. 


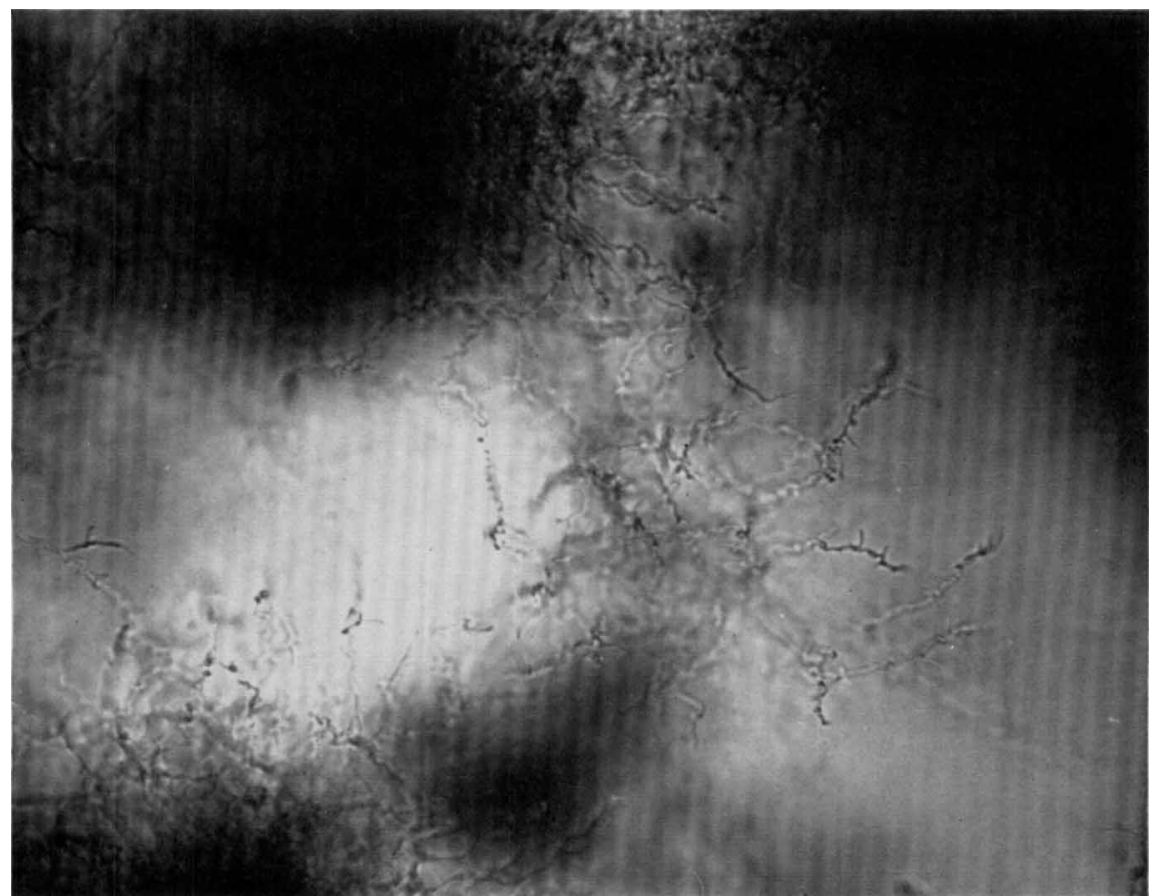

Fig. 1

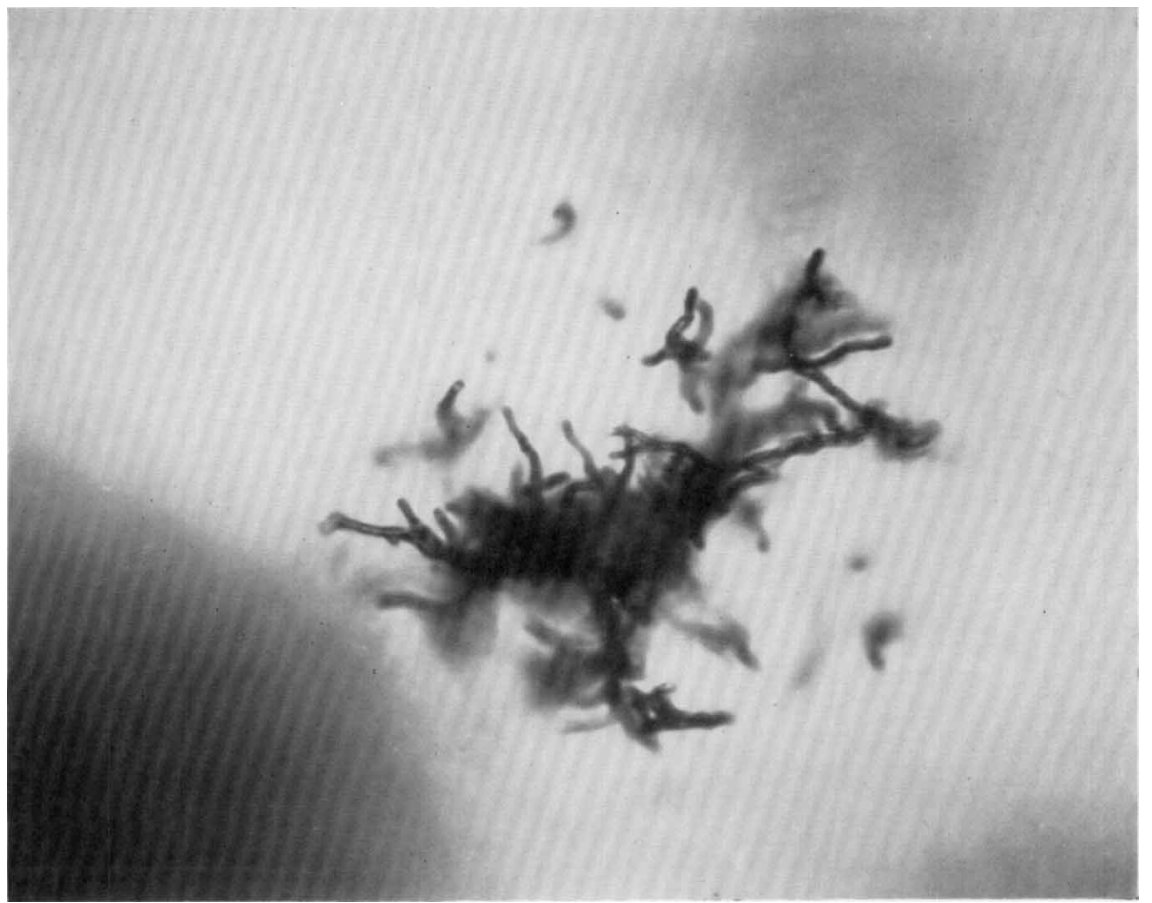

Fig. 2 
Journal of General Microbiology, Vol. 27, No. 1

Plate 2

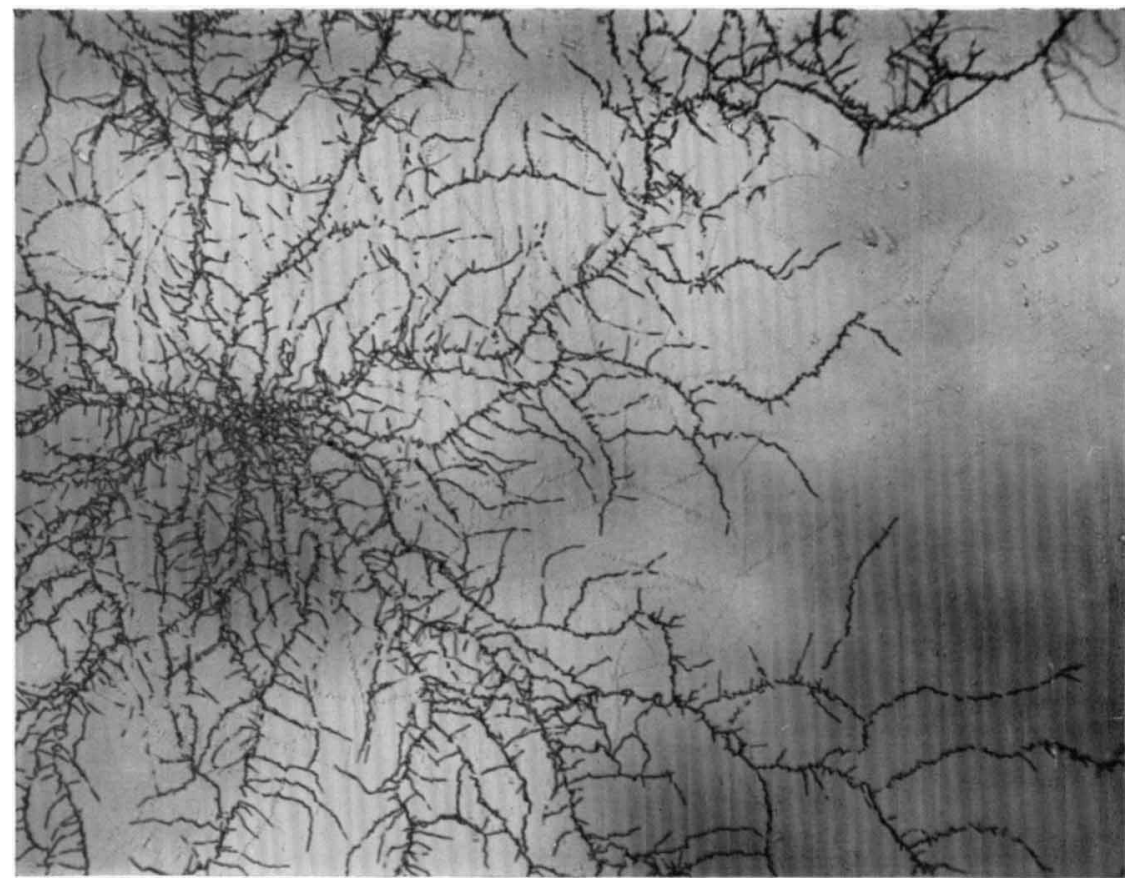

Fig. 3

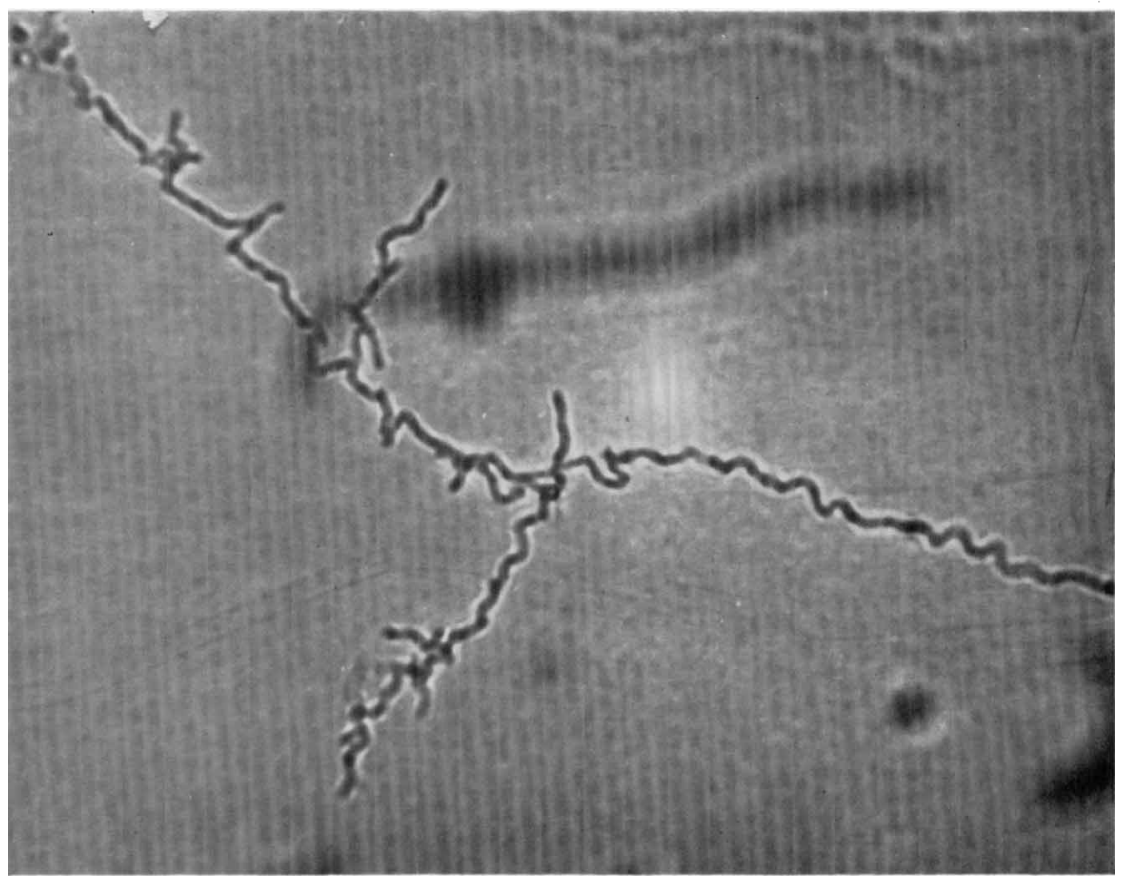

Iig. 4

R. E. GORDON AND J. M. MIHM 

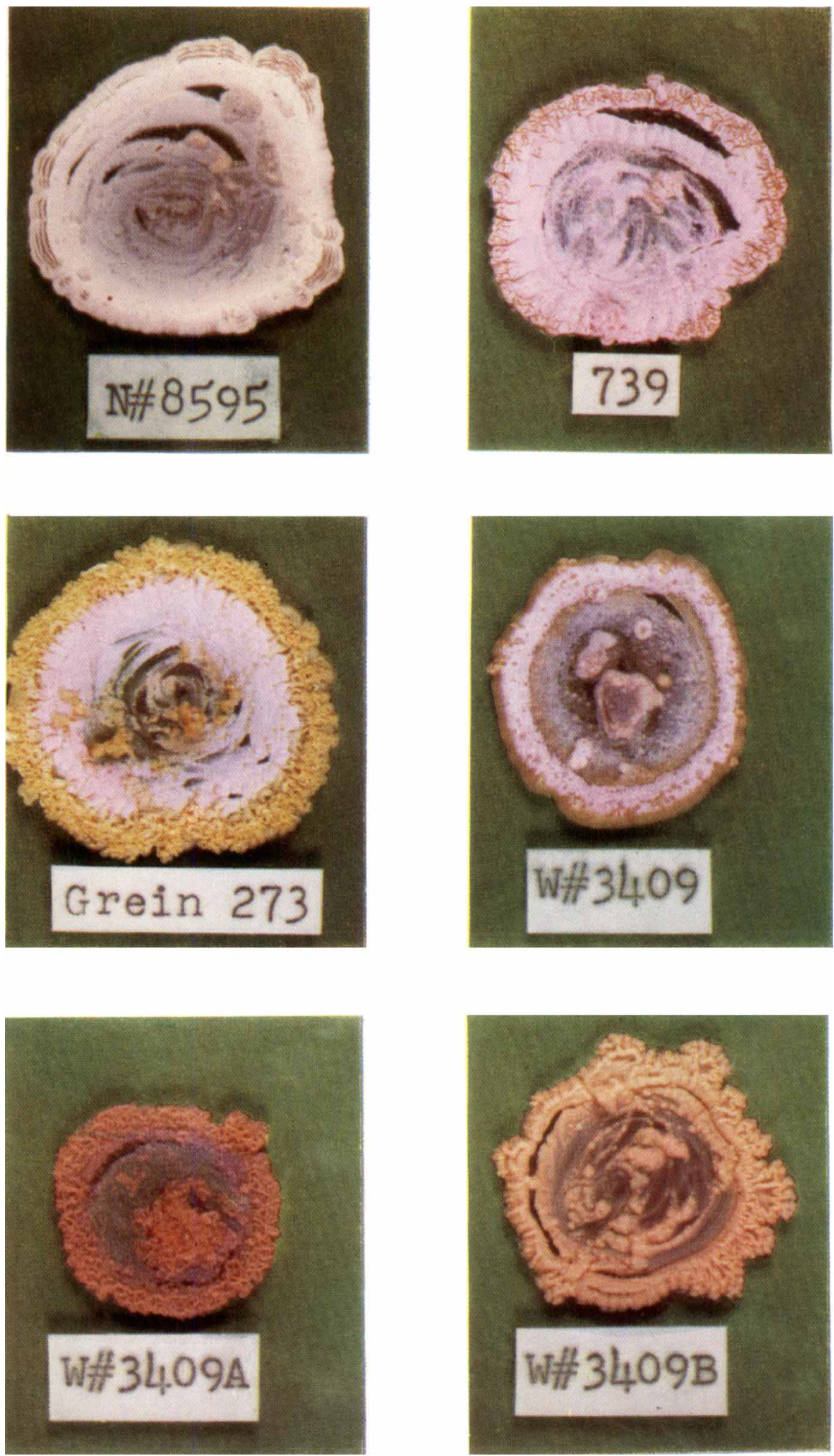

R. E. GORDON AND J. M. MIHM 

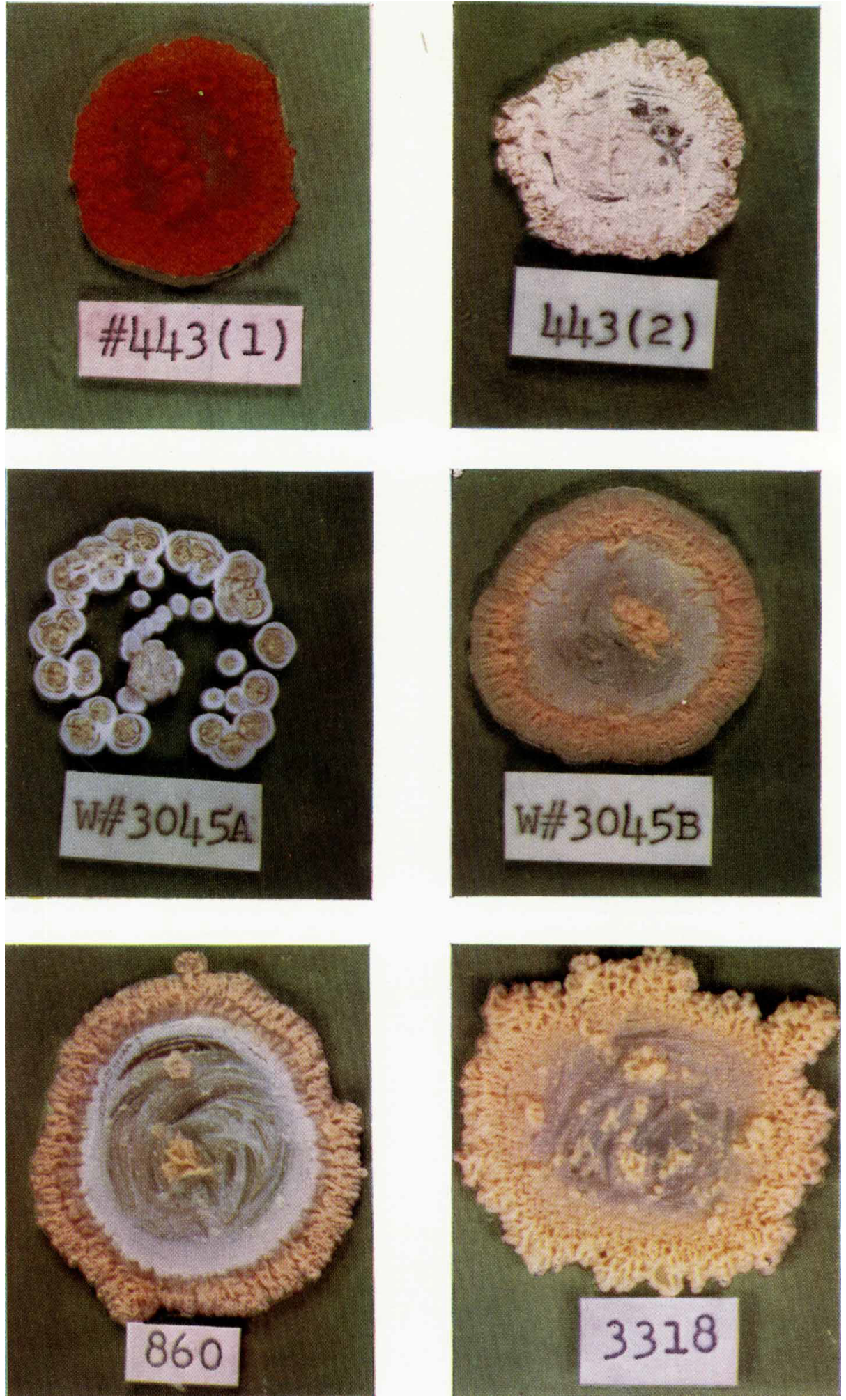

R. E. GORDON AND J. M. MIHM 

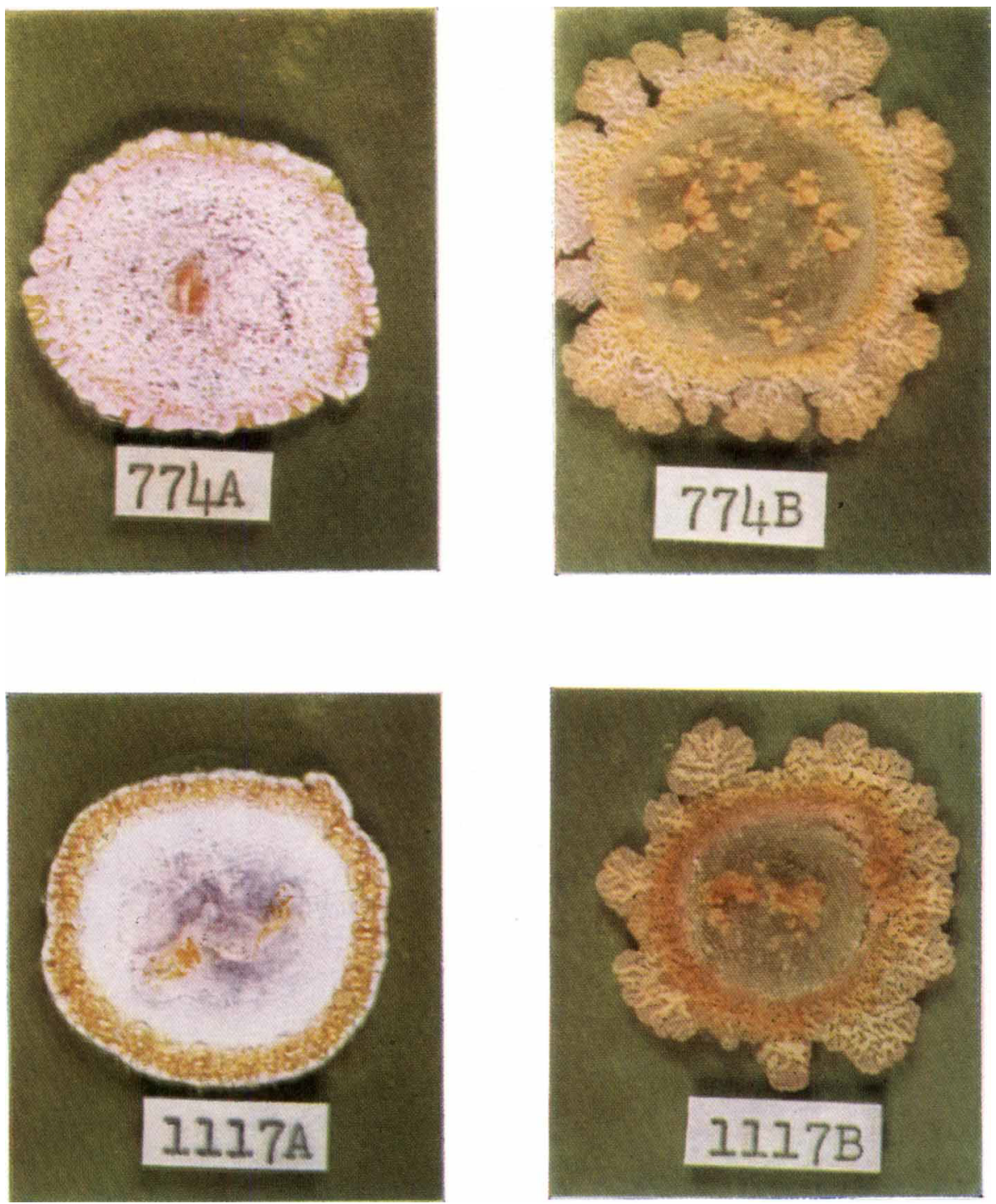

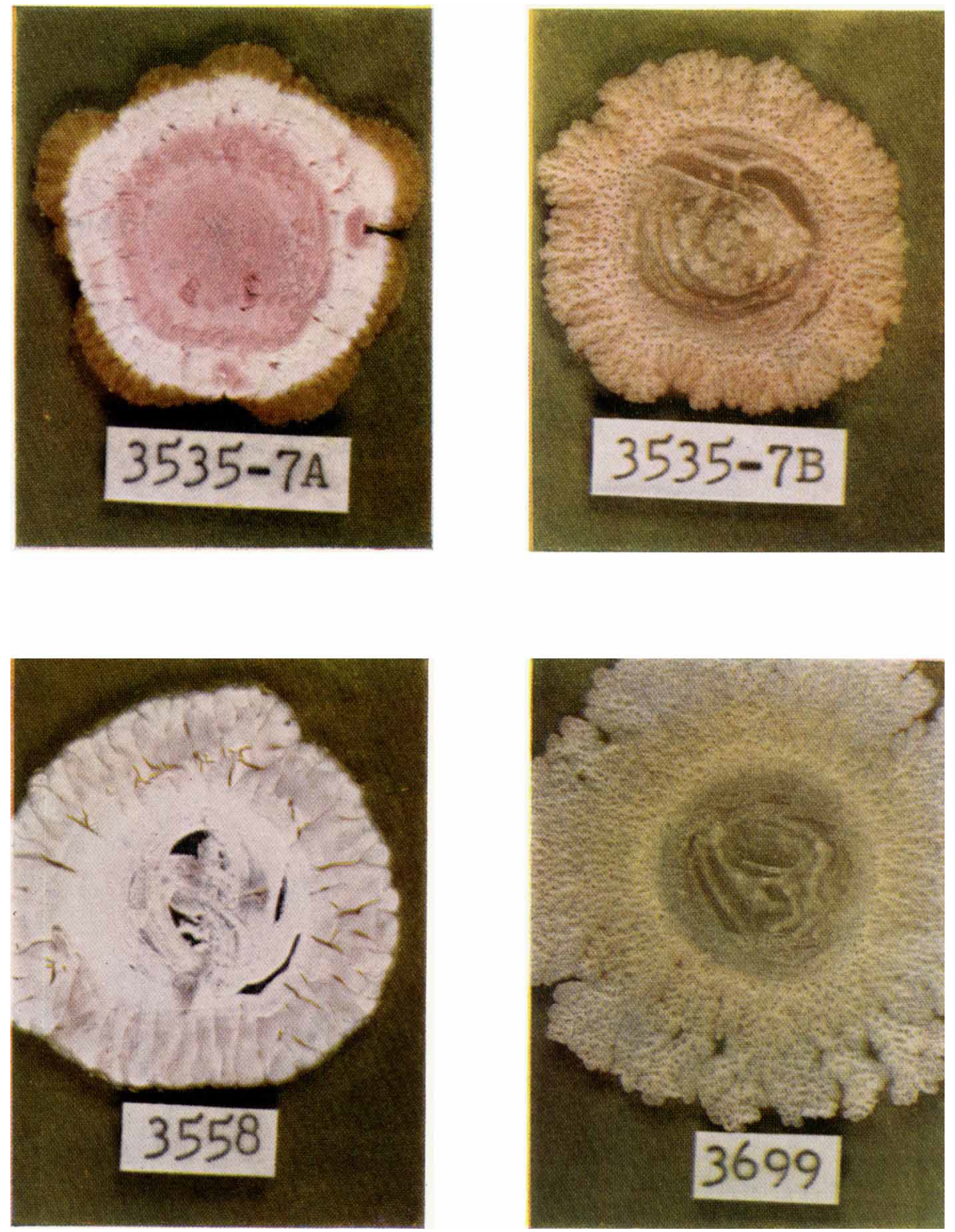